\title{
Survei Kondisi Fisik Kelincahan Pemain Futsal Undikma
}

\author{
${ }^{1}$ P. Muhammad Yusuf, ${ }^{2}$ Fadli Zainuddin \\ ${ }^{12}$ Fakultas Ilmu Keolahragaan dan Kesehatan Masyarakat, Universitas \\ Pendidikan Mandalika Mataram \\ Email: m.yusuf74@ rocketmail.com
}

\begin{abstract}
Abstrak. Futsal menuntut kondisi fisik yang prima bagi para pemainnya. Kondisi fisik yang prima sangatlah menunjang penampilan seorang pemain. Penampilan fisik yang buruk tentunya akan berdampak buruk juga bagi penampilan teknik dan taktiknya. Persiapan fisik merupakan suatu hal yang penting dalam masa persiapan sebuah tim untuk mencapai prestasi yang optimal. Kampus UNDIKMA merupakan salah satu kampus swasta yang ada di Provinsi Nusa Tenggara Barat yang memiliki fakultas olahraga dan kesehatan dan tempat pembinaan atlit futsal UNDIKMA. Hal ini dibuktikan dengan adanya kegiatan latihan futsal yang rutin. Melaui survei yang di lakukan setiap 3 bulan, tim futsal belum bisa konsisten untuk meraih prestasi di turnament futsal karena kondisi fisik kelincahan pemain belum merata. Tujuan dari penelitian ini adalah mengukur kondisi fisik kelincahan pemain futsal UNDIKMA. Sehingga dapat memastikan seberapa besar tingkat kelincahan para pemain dalam beberapa bulan berlatih. Dari hasil di atas kondisi fisik Kelincahan pemain futsal UNDIKMA dikategorikan masih di bawah rata rata, karena dari 15 jumlah pemain futsal hanya 1 orang yang kelincahannya di kategori baik dengan persentase $6,67 \%$. 5 orang di kategori sedang dengan persentase 33,33\%. 7 orang dengan kategori kurang dengan persentase $46,67 \%$ dan 2 orang dengan kategori kurang sekali dengan persentase 13,33\%.
\end{abstract}

Kata Kunci : Kelincahan, Futsal.

Abstrack. Futsal demands excellent physical condition for the players. Excellent physical condition is very supportive of the appearance of a player. Poor physical appearance will certainly also have a negative impact on technical performance and tactics. Physical preparation is important in the preparation period of a team to achieve optimal performance. The UNDIKMA campus is one of the private campuses in the province of West Nusa Tenggara that has a faculty of sports and health and a place to build UNDIKMA futsal athletes. This is proven by the existence of routine futsal training activities. Through a survey conducted every 3 months, the futsal team has not been able to consistently achieve achievements in the futsal tournament because the physical condition of the players' agility has not been evenly distributed. The purpose of this study was to measure the physical condition of the agility of futsal players UNDIKMA. So as to ascertain how big the level of agility of the players in a few months of training. From the results above, the physical condition of UNDIKMA futsal players was categorized as still below average, because of the 15 number of futsal players, only 1 person was good in agility with a percentage of $6.67 \%$. 5 people in the medium category with a percentage of $33.33 \%$. 7 people with less category with a percentage of $46.67 \%$ and 2 people with a very low category with a percentage of $13.33 \%$.

Keywords: Agility, Futsal.

\section{PENDAHULUAN}

Futsal menuntut kondisi fisik yang prima bagi para pemainnya. Kondisi fisik yang prima sangatlah menunjang penampilan seorang pemain. Penampilan fisik yang buruk tentunya akan berdampak buruk juga bagi penampilan teknik dan taktiknya. Persiapan fisik merupakan suatu hal yang penting dalam masa persiapan sebuah tim untuk mencapai prestasi yang optimal.

Futsal adalah permaianan bola yang dimainkan oleh dua tim, yang masing-masing tim beranggotakan lima orang dengan tujuan untuk memasukkan bola ke gawang lawan, 
dengan manipulasi bola dan kaki (Kurniawan, 2011:104). John D. Tenang (2008:17) menyatakan bahwa permainan olahraga futsal mengembangkan skill bermain futsal dari setiap pemain olahraga futsal itu sendiri. Andi Irawan (2009:5) menyatakan olahraga futsal adalah permainannyang sangat cepat dan dinamis.

Kampus UNDIKMA merupakan salah satu kampus swasta yang ada di Provinsi Nusa Tenggara Barat yang memiliki fakultas olahraga dan kesehatan dan tempat pembinaan atlit futsal UNDIKMA. Hal ini dibuktikan dengan adanya kegiatan latihan futsal yang rutin. Melaui survei yang di lakukan setiap 3 bulan, atlit tim futsal belum bisa konsisten untuk meraih prestasi di turnament futsal karena kondisi fisik kelincahan pemain belum merata. Dalam hal ini terdapat faktor yang mempengaruhi penampilan dalam pertandingan tersebut antara lain daya ledak kecepatan, kelincahan, daya tahan, kekuatan.

Pengkajian dalam penelitian ini diarahkan pada salah satu kondisi fisik dalam permainan futsal yaitu kelincahan komponen tersebut memiliki andil seberapa besar kondisi fisik para pemain futsal undikma dan diteliti secara praktek melalui praktek tes dan pengukuran yang tepat sehingga mendapatkan hasil yang tepat juga. Permasalahan dalam tim ini salah satunya adalah kelincahan.

Oleh karena itu tujuan dari penelitian ini adalah mengukur salah satu kondisi fisik kelincahan pada pemain futsal undikma. Sehingga dapat memastikan seberapa besar tingkat kelincahan para pemain dalam beberap bulan latihan.

Karena dalam beberapa bulan latihan banyak bentuk latihan khususnya latihan kelincahan yang diterapkan kepara pemain dengan asumsi latihan tersebut dapat meningkatkan segala spek kondisi fisik. Hipotesis yang dapat diajukan dalam penelitian ini adalah seberapa besar tingkat kelincahan para pemain futsal UNDIKMA

Dari permasalahan diatas peneltian ini akan mangangkat judul "survei kondisi fisik kelincahan pemain futsal Undikma.

\section{KAJIAN TEORI}

Kelincahan merupakan kemampuan untuk mengubah arah secara cepat tanpa menimbulkan gangguan pada keseimbangan. Seseorang dikatakan memiliki kelincahan jika ia dapat bergerak secara cepat sekaligus dapat mengubah arah secara cepat pula tanpa terganggu keseimbangannya. Beberapa orang dapat bergerak secara cepat tetapi mereka tidak dapat melakukan perubahan arah geraknya secara cepat, yang demikian tidak dapat dikatakan bahwa orang tersebut lincah.

Kelincahan adalah suatu kemapuan seseorang uantuk mengubah arah dan posisi sesuai dengan situasi yang dikehendaki atau dihadapi dengan cara secepat mungkin (Suharno : 1992) selain itu kelincahan menurut (Harsono : 1993) kemapuan untuk mengubah posisi dan arah tubuh dengan cepat secara tepat ketika sedang bergerak tanpa kehilangan keseimbangan maupun kesadaran akan posisi tubuhnya.

\section{METODE PENELITIAN}

Penelitian ini merupakan penelitian deskriptif kuantitatif dengan populasi 15 orang penain futsal UNDIKMA. Penelitian ini menggunakan studi populasi. Metode yang digunakan adalah survey dengan teknik pengumpulan data menggunakan tes dan pengukuran. Instrument yang digunakan dalam penelitian ini adalah mengukur kelincahan pemain futsal UNDIKMA. Untuk kelincahan menggunakan Shuttle Run digunakan untuk mengukur kelincahan para pemian. Alat yang digunakan adalah Cones, stopwatch, peluit dan lapangan berukuran 10 meter dengan permukaan yang rata.

\section{HASIL DAN PEMBAHASAN}

Untuk analisis data dalam penelitian ini, maka hasil tes kelincahan dengan shuttle run akan di masukkan ke dalam kategori sesuai tabel norma kelincahan.

\section{Tabel 1 hasil kelincahan}

\begin{tabular}{|c|l|c|}
\hline NO & \multicolumn{1}{|c|}{ NORMA } & PRESENSI (detik) \\
\hline 1 & BAIK SEKALI & Ke atas 12.10 \\
\hline 2 & BAIK & $12.11-13.53$ \\
\hline 3 & SEDANG & $13.54-14.96$ \\
\hline 4 & KURANG & $14.97-16.39$ \\
\hline 5 & KURANG SEKALI & $16.40-$ Ke bawah \\
\hline
\end{tabular}


Tabel 2 norma kelincahan

\begin{tabular}{|l|c|c|}
\hline KATEGORI & JUMLAH & PERSENTASE \\
\hline BAIK SEKALI & 0 & $0 \%$ \\
\hline BAIK & 1 & $6,67 \%$ \\
\hline SEDANG & 5 & $33,33 \%$ \\
\hline KURANG & 7 & $46,67 \%$ \\
\hline KURANG SEKALI & 2 & $13,33 \%$ \\
\hline & 15 & $100 \%$ \\
\hline
\end{tabular}

Setelah semua proses tes kelincahan maka data telah di peroleh untuk selanjutnya akan di masukkan dalam tabel tingkat persentase kelincahan pemain futsal UNDIKMA.

Tabel 3 Tingkat persentase kelincahan

\begin{tabular}{|c|c|c|c|}
\hline No & Nama & Pretest & Kategori \\
\hline 1. & A & 14,72 & Sedang \\
\hline 2. & B & 13,43 & Baik \\
\hline 3. & $C$ & 14,39 & Sedang \\
\hline 4. & D & 13,92 & Sedang \\
\hline 5. & $\mathrm{E}$ & 14,98 & Sedang \\
\hline 6. & F & 15,29 & Kurang \\
\hline 7. & $\mathrm{G}$ & 14,82 & Sedang \\
\hline 8. & $\mathrm{H}$ & 15,70 & Kurang \\
\hline 9. & I & 16,25 & Kurang \\
\hline 10 & J & 16,76 & $\begin{array}{c}\text { Kurang } \\
\text { Sekali }\end{array}$ \\
\hline 11. & $\mathrm{~K}$ & 15,21 & Kurang \\
\hline 12. & L & 15,67 & Kurang \\
\hline 13. & $\mathbf{M}$ & 16,65 & $\begin{array}{l}\text { Kurang } \\
\text { Sekali }\end{array}$ \\
\hline 14. & $\mathbf{N}$ & 14,13 & Kurang \\
\hline 15. & $\mathrm{O}$ & 16,25 & Kurang \\
\hline
\end{tabular}

Dari hasil di atas kondisi fisik Kelincahan pemain futsal UNDIKMA dikategorikan masih di bawah rata rata, karena dari 15 jumlah pemain futsal hanya 1 orang yang kelincahannya di kategori baik dengan persentase $6,67 \%$. 5 orang di kategori sedang dengan persentase $33,33 \%$. 7 orang dengan kategori kurang dengan persentase $46,67 \%$ dan 2 orang dengan kategori kurang sekali dengan persentase $13,33 \%$.

Oleh karena itu seseorang yang mampu mengubah arah dari posisi ke posisi yang berbeda dalam kecepatan tinggi dengan koordinasi gerak yang baik berarti kelincahannya cukup tinggi Sajoto (1988:90). Sedangkan menurut Dangsina Moeloek dan Arjadino Tjokro (1984: 8), kelincahan adalah kemampuan mengubah secara cepat arah tubuh atau bagian tubuh tanpa gangguan pada keseimbangan. Mengubah arah gerakan tubuh secara berulang-ulang seperti halnya lari bolak-balik memerlukan kontraksi secara bergantian pada kelompok otot tertentu.

Berdasarkan pembahasan di atas, pentingnya berlatih kelincahan untuk mencapai tujuan latihan yang diharapkan, sekaligus untuk mengetahui apakah ada peningkatan kelincahan pemain.

\section{KESIMPULAN}

Berdasarkan analisis data diatas dapat disimpulkan secara umum bahwa tingkat kondisi fisik pemain futsal UNDIKMA masih di bawah rata rata untuk seorang pemain futsal, oleh karena itu pemain dan pelatih harus tetap bekerja sama untuk menerapkan dan menjalankan program latihan agar kelincahan para pemain dapat meningkat untuk menunjang performa para pemain dalam mengikuti turnamen futsal dan dapat berprestasi.

\section{SARAN}

Melihat dari hasil penelitian ini, dapat disampaikan beberapa saran terhadap pemain dan pelatih khususnya tim futsal UNDIKMA. Kepada para pemain yang mengikuti penelitian ini menjadi sampel penelitian, diharapkan terus melanjutkan latihan agar kelincahan yang dimiliki semakin terus meningkat. Pelatih dapat meberikan latihan yang tepat bagi para pemain dalam meningkatkan kelincahan dalam bermain futsal.

\section{DAFTAR PUSTAKA}

Andi Irawan. 2009. Teknik Dasar Modern futsal. Jakarta. Pena PundiAngkasa

Tenang, John D. 2008. Mahir Bermain Futsal. Bandung: DAR Mizan

Dangsina Moeloek \& Arjadino Cokro. (1984). Kesehatan dan Olahraga. Jakarta: Fakultas. Kedokteran UI. Sajoto. (1988). Pembinaan Kondisi fisik dalam olahraga. Jakarta: Depdikbud.

Diakses hari rabu tanggal 29 april 2020. https://materipenjasorkes.blogspot.co $\underline{\mathrm{m} / 2014 / 06 / \text { kelincahan-manfaat-dan- }}$ bentuk-bentuk.html 